\title{
KẾT QUẢ PHẪU THUÂTT THAY VAN HAI LÁ DO HẸP BẰNG VAN NHÂN TẠO CO' HỌC ATS TẠI BỆNH VIỆN TRUNG ƯƠNG QUÂN ĐộI 108
}

\author{
Đoàn Quốc Hưng*, Nguyễn Quốc Hưng**, Trần Trọng Kiểm**
}

TÓM TẮT

Muc tiêu: Đánh giá một số đăc điểm đăc điểm lâm sàng, cận lâm sàng của các bệnh nhân hẹp van hai lá có chì định thay van cỡ học ÁTS Open Pivot và đánh giá kết quả sớm của phấu thuât thay van cơ hoc ATS Open Pivot trong điêu trị hẹp van hai lá tại Bệnh viên Trung ương Quân đọi 108. Đối tương: 76 bểnh nhân hẹp van hai lá được phẫu thuật thay van hai lá cơ học ATS Open Pivot tại Bệnh viện Trung ương Quân đội 108 từ tháng 12.2018 đến tháng 12.2020. Kết quả: Tuổi trung bình $50,79 \pm 7,53$ tuổi; nam nhiều hơn nữ. Hầu hết bệnh nhân có đố suy tim trước mổ NYHA II, III. Áp lực đổng mach phổi tâm thu tăng chủ yếu mức độ trung bình và nặng. Thời gian tuần hoàn ngoài cơ thể trung bình $113,48 \pm 25,42$ phút; thời gian cặp động mạch chủ trung bình 88,66 \pm 20,85 phút. Các biến chứng sớm hay gặp: chảy máu, biến chứng hô hấp, thần kinh. Tỷ lệ tử vong 1,3\%. Sau mổ: áp lực động mạch phổi tâm thu giảm, tình trang suy tim cải thiện. Kết luận: Thay van hai lá bằng van cơ học ATS Open Pivot là phương pháp điều trị tốt cho phần lớn bệnh nhân hẹp van hai lá với tỷ lệ biến chứng thấp, giảm tình trạng tăng áp lực động mạch phổi và suy tim theo thời gian.

Tư khóa: Thay van hai lá cơ học, van ATS, BVTW quân đội 108

\section{SUMMARY}

THE RESULT OF STENOSIS MITRAL REPLACEMENT BY ATS MECHANICAL VALVE AT 108 MILITARY CENTRAL HOSPITAL

Objectives:Evaluate some clinical and paraclinical characteristics of patients with mitral valve stenosis who are candidates for ATS Open Pivot mechanical valve replacement and results of this procedure at 108 Military Central Hospital. Patient and method: This is a descriptive, cross-sectional study of 76mitral valve stenosis patients who are candidates for ATS mechanical valve replacement at 108 Military Central Hospital from December 2018 to December 2020. Result: Mean age was $50,79 \pm 7,53$ years; the percentage of male patients is higher thanwomen. Most of the patients were in NYHA class II to III preoperatively. Systolic pulmonary artery pressure elevation was mainly in moderate and severe degree. Mean CPB time was $113,48 \pm 25,42 \mathrm{~min}$; cross-clamp time was $88,66 \pm 20,85 \mathrm{~min}$. Common early complications: bleeding complication, respiratory complication, neurological complication. Hospital death

*Trường Đại học Y Hà Nọi,

**Bênh viển TW Quân đội 108

Chịu trách nhiệm chính: Đoàn Quốc Hưng,

Email: hung.doanquoc@gmail.com

Ngày nhận bài: 3/4/2021

Ngày phản biên khoa hoc: 2/5/2021

Ngày duyệt bài: 28/5/2021 was $1,3 \%$. After surgery, systolic pulmonary artery pressure decreased and condition of heart failure also recovered. Conclusion: Mitral valve replacement, using ATS mechanical prothesis, is a good treatmen for most patients with mitral valve stenosis withlow complication rate,decreasing ofpulmonary artery pressure and recoveringheart failure over follow up time.

Key words. Mitral valve replacement, ATS mecanichal valve, 108 hospital

\section{I. ĐĂT VẤN ĐỀ}

Hẹp van hai lá giờ đây vẫn là một bệnh tim mạch phổ biến tại Việt Nam, nguyên nhân chủ yếu do thấp[1]. Bệnh gây nhiếu biến chứng nguy hiểm nếu không được phát hiên sớm và điều trị đúng. Sự ra đời của van hai lá nhân tạo (gồm van cơ họ và sinh hoc) tạo lên một bước tiến mới trong điều trị bệnh van hai lá, giúp điêu trị triệt để cho các bệnh nhân tổn thương van hai lá nặng mà không thể nong hoặc sửa van được. Từ thế hê van cơ học thương mại đầu tiên của Starr-Edward được giới thiệu năm 1961 dạng bi lồng, đến năm 1977 là sự ra đời của thế hệ van cơ học dạng 2 cánh SJM có nhiều ưu điểm vượt trội[2],[3].

Van ATS Open Privot của hãng ATS Medical (Minneapolis, Minnessota,Mỹ)cũng là van cơ học dạng hai lá được phát triến từ năm 1992 có nhiều cải tiến: chiều cao thấp, trụ xoay kiểu gờ nổi, cánh van hoàn toàn di chuyển trong giới hạn khung van. Các nghiên cứu trước đây đã đánh giá van ATS Open Privot có một số ưu điểm: tỷ lệ biến chứng huyết khối và tan máu thấp, tiếng ồn do sự di chuyển cánh van nhỏ[2],[3],[4]. Bênh việnTrung ương Quân đội 108 đã đưa van hái lá cớ học ATS Open Privot vào phấu thuật thay van tim từ năm 2014. Sau một thời gian sử dụng, chúng tôi tiến hành nghiên cứu này nhằm: Nhận xét một số đặc điểm bênh lý của nhóm bệnh nhân và đánh giá kết quả sớm của phẫu thuật thay van hai lá do hẹp bằng van nhân tạo ATS Open Privot tại Bệnh viện Trung ương quẩn đội 108.

\section{II. ĐỐI TƯỢNG VÀ PHƯƠNG PHÁP NGHIÊN CỨU}

2.1. Đối tượng nghiên cứu: Gồm tất cả bệnh nhân hẹp van hai lá được phẫu thuật thay van hai lá bằng van nhân tạo cơ học ATS Open Privottại Bệnh viện Trung ương Quân đội 108 (kể cả bệnh nhân có tiền sử nong van hay thay hoặc sửa van) từ tháng 12/2018 đến tháng 12/2020.

\subsection{Phương pháp nghiên cứu}

- Nghiên cứu hồi cứu, mô tả cắt ngang, 
không có đối chứng. Phương pháp chọn cõ̃ mẫu thuận tiện lấy hết các bệnh nhân đủ tiêu chuẩn trong thời gian nghiên cứu.

- Đánh giá các chỉ số: dịch tễ, lâm sàng, cận lâm sàng, đặc điểm trong mổ và kết quả sớm sau phẫu thuật. Các số liệu được phân tích trên phần mềm SPSS 20.0.

\section{KẾT QUẢ NGHIÊN CứU}

Từ tháng 12/2018 đến tháng 12/2020 tại Khoa Phẫu thuật tim mạch, Bệnh viện Trung ương Quân đội 108 có 76 bệnh nhân đủ tiêu chuẩn nghiên cứu với các đặc điểm như sau.

\subsection{Một}

- Độ tuổi trung bình là $50,79 \pm 7,53$. Tỷ lệ nam/nử là 53,9\% / 46,1\%.

- Bệnh nhân sống thành thị chiếm 57,9\%; nông thôn là $42,1 \%$. Bệnh nhân là quân nhân hoặc quân hưu chiếm 19,7\%; đối tượng khác là $80,3 \%$.

Bảng 1. Một số đặc điểm lâm sàng trước phẫu thuật $(N=76)$

\begin{tabular}{|c|c|c|}
\hline \multicolumn{2}{|c|}{ Đặc điểm bệnh nhân } & \multirow{2}{*}{\begin{tabular}{|c}
$\begin{array}{c}\text { Số bệnh } \\
\text { nhân (\%) }\end{array}$ \\
$15(19,7)$
\end{tabular}} \\
\hline \multirow{4}{*}{$\begin{array}{l}\text { Tiên } \\
\text { sử }\end{array}$} & Thấp tim được chấn đoán & \\
\hline & Nong van hai lá qua da & $7(9,2)$ \\
\hline & Nong van tim kín & $1(1,3)$ \\
\hline & Biến chứng mach ngoai vi & $13(17,1)$ \\
\hline \multirow{2}{*}{$\begin{array}{c}\text { Tiếng } \\
\text { tim }\end{array}$} & Rung tâm trương & $68(89,5)$ \\
\hline & Tiếng thối tâm thu & $27(35,5)$ \\
\hline \multicolumn{2}{|c|}{$\begin{array}{c}\text { Suy tim phải (gan to, phù, TM } \\
\text { cố nổi) }\end{array}$} & $76(100)$ \\
\hline \multirow{4}{*}{ NYHA } & I & $0(0)$ \\
\hline & II & $47(61,8)$ \\
\hline & III & $28(36,9)$ \\
\hline & IV & $1(1,3)$ \\
\hline \multirow{3}{*}{ BMI } & Thiếu cân & $16(21,1)$ \\
\hline & Bình thường & $41(53,9)$ \\
\hline & Thừa cân & $19(25)$ \\
\hline
\end{tabular}

- Đặc điểm điện tim trước mố: nhịp xoang là 30,3\%. Rung / cuồng nhĩ: 69,7\%

Bảng 2. Đánh giá siêu âm trước mổ $(N=76)$

\begin{tabular}{|c|c|}
\hline Đặc điểm siêu âm & $\begin{array}{c}\text { Thông số nhóm } \\
\text { N }(\%) \text { (nhỏ nhất- } \\
\text { lớn nhất) }\end{array}$ \\
\hline Huyết khối tiếu nhĩ/nhĩ trái & $11(14,5 \%)$ \\
\hline Hớ van ba lá nặng & $22(28,9 \%)$ \\
\hline $\begin{array}{c}\text { Chênh áp trung bình qua VHL } \\
\text { MeanPG (mmHg) }\end{array}$ & $\begin{array}{c}10,35 \pm 3,85 \\
(3-19)\end{array}$ \\
\hline $\begin{array}{c}\text { Ap lực ĐMP tâm thu - PAPs } \\
\text { (mmHg) }\end{array}$ & $\begin{array}{c}43,64 \pm 12,65 \\
(26-94)\end{array}$ \\
\hline Phân suất tống máu EF(\%) & $\begin{array}{c}59,82 \pm 10,72 \\
(39-82)\end{array}$ \\
\hline Đường kính nhĩ trái (mm) & $\begin{array}{c}48,79 \pm 10,49 \\
(25-87)\end{array}$ \\
\hline Đường kính thất trái tâm thu - & $49,33 \pm 9,11$ \\
\hline
\end{tabular}

\begin{tabular}{|c|c|}
\hline Dd (mm) & $(30-74)$ \\
\hline $\begin{array}{c}\text { Đường kính thất trái tâm } \\
\text { trương }- \text { Ds }(\mathrm{mm})\end{array}$ & $33,39 \pm 8,41$ \\
\hline Đường kính thất phải $(\mathrm{mm})$ & $25,32 \pm 6,14$ \\
& $(13-46)$ \\
\hline Điểm Wilkins & $9,39 \pm 0,83$ \\
& $(8-12)$ \\
\hline Diện tích lỗ van hai lá $\left(\mathrm{cm}^{2}\right)$ & $0,87 \pm 0,21$ \\
& $(0,5-1,2)$ \\
\hline ĐK vòng van ba lá $(\mathrm{mm})$ & $31,32 \pm 5,66$ \\
& $(24-44)$ \\
\hline
\end{tabular}

3.2. Đă̆c điếm trong phẫu thuật

Bảng 3. Cỡ van hai lá ATS sử dựng $(N=76)$ Cõ̃ van

ATS 25

Số bệnh nhân(\%)

ATS 27

ATS 29

ATS $31 \quad 17(22,4)$

ATS $33 \quad 2(2,6)$

Bảng 4. Các phẫu thuật phôi hợp $(N=76)$

\begin{tabular}{|c|c|}
\hline Loại phâuu thuật & Số bệnh nhân (\%) \\
\hline Sửa van ba lá & $35(46)$ \\
\hline Phâ̂u thuật MAZE & $37(48,7)$ \\
\hline Khâu chân tiếu nhĩ trái & $55(72,4)$ \\
\hline
\end{tabular}

Bảng 5. Đặc điểm thời gian trong phẫu thuật $(N=76)$

\begin{tabular}{|c|c|c|c|c|}
\hline $\begin{array}{c}\text { Chỉ số nghiên } \\
\text { cứu }\end{array}$ & $\begin{array}{l}\text { Nhỏ } \\
\text { nhất }\end{array}$ & $\begin{array}{l}\text { Lớn } \\
\text { nhất }\end{array}$ & $\begin{array}{c}\text { Trung } \\
\text { bình }\end{array}$ & $\begin{array}{c}\text { Độ } \\
\text { lệch } \\
\text { chuẩn }\end{array}$ \\
\hline $\begin{array}{l}\text { Tuần hoàn ngoài } \\
\text { cơ thể (phút) }\end{array}$ & 62 & 220 & 113,89 & 25,42 \\
\hline $\begin{array}{l}\text { Thời gian cặp đống } \\
\text { mạch chú (phút) }\end{array}$ & 42 & 160 & 88,66 & 20,85 \\
\hline $\begin{array}{l}\text { Tống thời phâu } \\
\text { thuật (phút) }\end{array}$ & 98 & 280 & 147,86 & 25,1 \\
\hline
\end{tabular}

rung/cuồng nhĩ: $14,5 \%$.

3.3. Kết quả sớm sau phẫu thuật

Bảng 6. Một số thông số sau mố( $(N=76)$

Đặc điếm bệnh nhân Thông số của nhóm

Thời gian thở máy (h) $13,47 \pm 6,36(6-36)$

Huyểt động ốn định $\quad 69(90,8 \%)$

\begin{tabular}{ll} 
Số lượng máu truyên (ml) & $689,47 \pm 357,99(0-2000)$ \\
\hline
\end{tabular}

Tổng dẫn lưu (ml) $684,14 \pm 267,7$ $(200-1500)$

Thời gian nằm tại Hồi $\quad 2,03 \pm 0,70$ sức (ngày)

Thời gian năm viện sau $\quad 11,75 \pm 2,98$ mổ (ngày)

$(1-21)$

Bảng 7. Các thông số siêu âm thời điềm ra viện $(N=75)$

Đặc điếm siêu âm $\quad$ Thông số nhóm

Hở van ba lá nặng

Chênh áp trung bình qua

VHL nhân tạo $(\mathrm{mmHg})$
$4,85 \pm 1,56(2-9)$

$5(6,67 \%)$




\begin{tabular}{|c|c|}
\hline Ap lực ĐMP tâm thu - & $35,28 \pm 8,37$ \\
PAPs (mmHg) & $(19-59)$ \\
\hline Phân suất tống máu $\mathrm{EF}(\%)$ & $58,59 \pm 11,67(21-89)$ \\
\hline Đường kính nhĩ trái $(\mathrm{mm})$ & $41,86 \pm 7,93(25-67)$ \\
\hline Đường kính thất trái tâm & $46,72 \pm 7,9$ \\
thu - Dd (mm) & $(31-66)$ \\
\hline $\begin{array}{c}\text { Đường kình thất trái tâm } \\
\text { trương - Ds }(\mathrm{mm})\end{array}$ & $32,11 \pm 7,96$ \\
\hline Đường kính thất phải $(\mathrm{mm})$ & $25,09 \pm 5,7(15)$ \\
\hline Diện tích lố van nhân tạo & $2,69 \pm 0,4$ \\
\hline (cm $\left.^{2}\right)$ & $(1,8-3,6)$ \\
\hline Hở cạnh van nhân tạo & $4(5,33 \%)$ \\
\hline
\end{tabular}

Bảng 8. Các biến chứng trong và sau mô $(N=76)$

\begin{tabular}{|c|c|c|}
\hline \multicolumn{2}{|c|}{ Nhóm biến chứng } & $\begin{array}{c}\text { Số bệnh } \\
\text { nhân (\%) }\end{array}$ \\
\hline \multicolumn{2}{|c|}{ Chảy máu (phải mố lại) } & $9(11,8)$ \\
\hline $\begin{array}{c}\text { Biến chứng } \\
\text { hố hấp }\end{array}$ & TDMP phải hút/DL & $22(28,9)$ \\
\cline { 2 - 3 } & Viêm phối & $6(7,9)$ \\
\hline \multicolumn{2}{|c|}{ Tan máu sau mố } & $1(1,3)$ \\
\hline \multicolumn{2}{|c|}{ Suy thận (phải looc máu) } & $2(2,6)$ \\
\hline \multicolumn{2}{|c|}{ Biến chứng thần kinh } & $6(7,9)$ \\
\hline \multicolumn{2}{|c|}{ Sốt sau mố } & $1(3,13)$ \\
\hline \multirow{2}{*}{$\begin{array}{c}\text { Nhiễm } \\
\text { khuẩn NK vết mố }\end{array}$} & $9(11,8)$ \\
\cline { 2 - 3 } & NK huyết & $0(0)$ \\
\cline { 2 - 3 } & NT xương ức & $0(0)$ \\
\hline \multicolumn{2}{|c|}{ Tứ vong } & $1(1,3)$ \\
\hline
\end{tabular}

Bảng 9. So sánh một số đặc điếm siêu âm trước và sau mổ

\begin{tabular}{|c|c|c|c|}
\hline $\begin{array}{c}\text { Đặc điếm } \\
\text { siêu âm }\end{array}$ & $\begin{array}{l}\text { Trước mố } \\
(\mathbf{N}=76)\end{array}$ & $\begin{array}{c}\text { Sau mố (N } \\
=75)\end{array}$ & $\mathbf{P}$ \\
\hline $\begin{array}{l}\text { ALĐMPTT } \\
(\mathrm{mmHg})\end{array}$ & $\begin{array}{c}43,64 \pm \\
12,65\end{array}$ & $\begin{array}{c}35,28 \pm \\
8,37\end{array}$ & $<0,05$ \\
\hline $\begin{array}{l}\text { Chỉ số } \\
\text { EF(\%) }\end{array}$ & $\begin{array}{c}59,82 \pm \\
10,72\end{array}$ & $\begin{array}{c}58,59 \pm \\
11,67\end{array}$ & $>0,05$ \\
\hline $\begin{array}{c}\text { Đường kính } \\
\text { NT (mm) }\end{array}$ & $\begin{array}{c}48,79 \pm \\
10,49 \\
\end{array}$ & $\begin{array}{c}41,86 \pm \\
7,93 \\
\end{array}$ & $<0,05$ \\
\hline $\mathrm{Dd}(\mathrm{mm})$ & $49,33 \pm 9,11$ & $46,72 \pm 7,9$ & $>0,05$ \\
\hline Ds (mm) & $33,39 \pm 8,41$ & $32,11 \pm 7,96$ & $>0,05$ \\
\hline $\begin{array}{l}\text { Đường kính } \\
\text { TP (mm) }\end{array}$ & $\begin{array}{c}25,32 \pm \\
6,14\end{array}$ & $\begin{array}{c}25,09 \pm \\
5,7\end{array}$ & $>0,05$ \\
\hline
\end{tabular}

Bảng 10. Anh hưởng của tiếng van tim $c 0$ hoc đến sinh hoat của bênh nhân sau mổ $(N=75)$

\begin{tabular}{|c|c|c|}
\hline Mức độ ảnh hưởng & $\begin{array}{c}\text { Số } \\
\text { BN }\end{array}$ & $\begin{array}{c}\text { Tỷ lộ } \\
\text { \% }\end{array}$ \\
\hline Không đế ý & 26 & 34,67 \\
\hline Nghe thấy, không ảnh hưởng gì & 40 & 53,33 \\
\hline Hơi khó chịu, khó ngủ & 6 & 8 \\
\hline Rất phiền phức, gây mất ngủ & 3 & 4 \\
\hline
\end{tabular}

\section{BÀN LUẬN}

4.1. Một số đặc điểm bệnh lý của nhóm bệnh nhân

- Độ tuổi của nhóm nghiên cứu 50,79 \pm 7,53 phù hợp nguyên nhân chủ đạo gây tổn thương van hai lá ở Việt Nam là bệnh lý thấp tim, gặp trong nhóm tuổi trung niên, bệnh nhân bị thấp từ nhỏ, không được phòng thấp tốt, bệnh tiến triển dần và đến tuổi trung niên thì tổn thương van tim nặng lên. Độ tuổi trung bình này cao hơn các nghiên cứu trước kia: Nguyễn Đức Hiền (2007)[5]: $36,78 \pm 10,25$ hay Đặng Hanh Sơn (2006-2007)[6]: 43,58 $\pm 11,01$ là do các lứa tuổi sau này tỷ lệ thấp tim càng ngày càng giảm, sự phát triển của kinh tế và y tế cũng như ý thức của người dân.

- Trong nghiên cứu của chúng tôi, tỷ lệ bệnh nhân sống thành thị $(57,9 \%)$ cao hơn nông thôn là do đặc thù của bệnh viện quân đội, số thẻ bảo hiểm của quân nhân, quân hưu, thân nhân nhiều.

- Nguyên nhân của hep van hai lá chủ yếu do thấp tim[1]. Tuy nhiên trong nhóm bênh nhân chúng tôi khảo sát chỉ 19,7\% được chẩn đoán trước đó (bảng 1), tức là một tỷ lẹ̣ rất lớn bệnh nhân không hề được phát hiện và quản lý thấp, nghiên cứu trên bềnh nhân bệnh van tim mắc phải của Đoàn Quốc Hưng và cộng sự tại Bệnh việt Việt Đức (2008-2011) thì tỷ lệ thấp tim khai thác được là $31,6 \%[7]$. Tỷ lệ tai biến do huyết khối gây tắc mach mạch ngoại vi trong tiền sử của nhóm bệnh nhân là khá cao: 17,1\% (với nhiều vị trí: mạch não, mạch chi, mạch tạng), điêu đó cho thấy mức độ trầm trọng do bệnh gây ra đặc biệt khi không được chẩn đoán và quản lý tốt.

- Khám lâm sàng khi vào viên hầu hết có tiếng rung tâm trương ở mỏm $(89,5 \%)$ rất đặc trưng của hep van hai lá [1], số ít bênh nhân do lá van dày dính quá mức gây hạn chế di chuyển, không nghe được. Bên cạnh đó có 35,5\% tiếng thổi tâm thu mỏm do hở van hai lá kết hợp (bảng 1), vì tổn thương do thấp thường kết hợp giữa hẹp và hở, tuy nhiên nhóm bệnh nhân của chúng tôi chỉ lấy những bệnh nhân hẹp van hai lá là chủ yếu, do đó hở chỉ ở mức độ nhe hoă̆c vừa. Biểu hiện lâm sàng trước mổ đều là NYHA II và III, không có bệnh nào có biểu hiện NYHA I, 1 bệnh nhân NYHA IV, tương đương nghiên cứu của Đặng Hanh Sơn[6], nguyên nhân là bênh nhân có tổn thương van tim kèm theo NYHA I thường không có chỉ định phẫu thuật còn những bệnh nhân có suy tim quá nặng (NYHA IV) thường được điều trị nội khoa tích cực trước khi phẫu thuật, 1 bênh nhân NYHA IV là vào cấp cứu, huyết động không ổn định, điều trị nội khoa không đáp ứng.

- Biểu hiện cận lâm sàng trước mổ: tỷ lệ rất cao bênh nhân rung nhĩ/cuồng nhĩ $(69,7 \%)$, huyết khối tiểu nhĩ/nhĩ trái (14,5\%), hở van ba lá 
phải can thiệp (28,9\%). Đây đều là hậu quả của hẹp van hai lá kéo dài, các đặc điểm này cũng làm tăng chỉ định phẫu thuật vì những bệnh nhân có huyết khối buồng tim hoặc có chỉ định phẫu thuật khác kèm theo thì không có chỉ định nong van hai lá bằng bong qua da, theo Đoàn Quốc Hưng thì tỷ lệ loạn nhịp nhóm bệnh van tim mắc phải là $85 \%[7]$. Các chỉ số siêu âm khác: chênh áp trung bình qua van $(10,35 \pm 3,85 \mathrm{mmHg})$, áp lực DMPTT $(43,64 \pm 12,65 \mathrm{mmHg})$, điều này cho thấy các bệnh nhân mắc bệnh lâu ngày gây những biến đổi về cấu trúc và chức năng tim nặng nề, tuy nhiên phân suất tống máu vẩn còn duy trì $(59,82 \pm 10,72 \%)$ do các bệnh nhân được điều trị nội khoa tốt. Điểm Wilkins trước mổ cao $(9,39 \pm 0,83)$ và diện tích lỗ van rất hẹp $(0,87 \pm$ $\left.0,2 \mathrm{~cm}^{2}\right)$ do đây là nhóm bệnh nhân không còn chỉ định nong van hai lá, tổn thương van và cấu trúc dưới van rất nặng nề do thấp.

\subsection{Các đặc điểm trong mổ}

- Các cõ̃ van được sử dụng nhiêu nhất là cõ van ATS 29 (47,9\%) và van cõ 31 (22,4\%) (bảng 3), điều này rất phù hợp với thể trạng người châu Á, nghiên cứu của Yuichiro Kaminishi (Nhật,
2009) thì tỷ lệ thay van hai lá ATS 29 là 41\%[4].

- Tại Bệnh viện 108, phẫu thuật MAZE điêuu trị rung nhĩ trong mổ tim mở đã được làm thường quy nhiều năm này, nhóm nghiên cứu của chúng tôi có $48,7 \%$ bệnh nhân được phẫu thuật MAZE. Tỷ lệ sửa van ba lá là $46 \%$ (chủ yếu là kỹ thuật thu nhỏ vòng van bằng đặt vòng van nhân tạo)tỷ lệ sửa cao hơn so với đánh giá trên siêu âm $(28,9 \%)$ do khi mở buồng tim ra phẫu thuật viên đánh giá thêm trên đo đường kính vòng van và thử bơm nước đánh giá độ hở, theo nghiên cứu của tác giả Nguyễn Đức Hiền tỷ lệ sửa van ba lá trong mổ cũng cao hơn đánh giá siêu âm trước mổ[5]. Tỷ lệ đóng chân tiểu nhĩ là: $72,4 \%$ (bảng 4), do tất cả các bệnh nhân rung nhî, có nguy cơ huyết khối hoặc có biến cố tắc mạch ngoại vi trước mổ đều được khâu đóng chân tiểu nhĩ dự phòng huyết khối sau này.

- Thời gian tuần hoàn ngoài cơ thể, thời gian cặp động mạch chủ của nhóm chúng tôi cao hơn một số nghiên cứu khác[5],[6],[7],[8]. Điều này có thể được giải thích là do tỳ lệ phấu thuật MAZE và đặt vòng van ba lá trong nhóm nghiền cứu cao, làm tăng thêm các khoảng thời gian.

\begin{tabular}{|c|c|c|c|}
\hline & Tg THNCT & Tg că̆p ĐMC & Tống Tg phâu thuật \\
\hline Chúng tôi (bảng 5) & $113,89 \pm 25,42$ & $88,66 \pm 20,85$ & $147,86 \pm 25,10$ \\
\hline Nguyến Đức Hiền[5] & $84,34 \pm 19,92$ & $62,20 \pm 13,17$ & \\
\hline Đặng Hanh Sơn[6] & $84,91 \pm 29.20$ & $62,85 \pm 20,69$ & \\
\hline Nguyên Văn Hai[8] & $95,60 \pm 32,10$ & $60,30 \pm 26,50$ & $123,50 \pm 33,50$ \\
\hline Đoàn Quốc Hưng[7] & $72,59 \pm 29,16$ & & \\
\hline
\end{tabular}

\subsection{Kết quả sớm sau mổ}

- Các biến chứng trong và ngay sau mổ hay gặp của nhóm nghiên cứu là: chảy máu phải mổ lại cầm máu $(11,9 \%)$, tràn dịch màng phổi phải chọc / dẫn lưu $(28,9 \%)$ và nhiễm khuẩn vết mổ $(11,8 \%)$. Một số biến chứng ít gặp hơn: suy thận phải lọc máu, biến cố thần kinh (bảng 8). Trong đó có một bệnh nhân tử vong sau mổ 24h, đây là một bệnh nhân thất trái nhỏ, sau mổ bị suy tim cấp gây suy đa tạng, trường hợp này rất đáng tiếc do không tiên lượng tốt trước nên khi hồi sức để khi tình trạng diễn biến nặng và nhanh xảy ra đã không cứu được bệnh nhân. Tỷ lệ biến chứng của chúng tôi cao hớn của Đoàn Quốc Hưng (mổ lại cầm máu: 2,6\%, nhiễm trùng vết mổ: 7,7\%; tử vong trong 30 ngày sau mồ: $0,9 \%)[7]$.

- Một số các thông số sau mổ (bảng 6,7 và 10):

+ Thời gian thở máy $13,47 \pm 6,36$ giờ, nằm viện $11,75 \pm 2,98$ ngày. Kết quả này tương ứng các nghiên cứu khác về phẫu thuật tim[3].

+ Lượng máu truyền sau mổ là: 689,47 \pm 357,99 ml, nguyên nhân là do chảy máu sau mổ còn cao $(11,8 \%)$ và lượng dẫn lưu sau mổ là $684,14 \pm 267,7 \mathrm{ml}$, các trường hợp này thường là chảy máu nội khoa ở bệnh nhân rung nhĩ dùng thuốc chống đông kéo dài trước mổ hoặc do thời gian chạy máy THNCT kéo dài.

+ Các chỉ số đánh giá trên siêu âm ở thời điểm xuất viện cho thây sự cải thiện các chỉ số như: phân suất tống máu, đường kính các buồng tim là không có ý nghĩa, chỉ có áp lực động mạch phổi tâm thu và đường kính nhĩ trái là giảm có ý nghĩ thống kê. Các nghiên cứu đều chỉ ra rằng chỉ có áp lực động mạch phổi là cải thiện sớm, các chỉ số khác sẽ cải thiện dần sau đó[3]. Diện tích lỗ van nhân tạo trung bình là $2,69 \pm 0,4 \mathrm{~cm}^{2}$ và chỉ có $5,33 \%$ hở nhẹ cạnh van cho thấy việc chọn cõ̃ van và kỹ thuật khâu của chúng tôi là khá đảm bảo.

+ Đặc biệt tại thời điểm xuất viện, khi được khảo sát có tới 34,67\% không hề đề ý thây tiêng van sau mổ; $53,33 \%$ nghe thấy nhỏ không ảnh hưởng sinh hoạt; $8 \%$ hơi khó ngủ do tiếng van gây ra và chỉ có $4 \%$ gây khó chịu, mất ngủ. Điều đó cho thấy tiếng ồn do van ATS Open Pivot gây 
ra là khá nhỏ.

+ Đánh giá NYHA sau mổ thời điểm xuất viện có đến 92,1\% NYHA I, có sự cải thiện rõ rệt khi trước mổ là 98,7\% NYHA II và III.

+ Vấn đề điêuu chỉnh thuốc chống đông cho bệnh nhân trước khi ra viện cũng rất được quan tâm với chỉ số INR là $2,81 \pm 0,64$ với liều Sintrom trung bình là $1,48 \pm 0,35 \mathrm{mg}$.

\section{KẾT LUÂ̂N}

Hẹp van hai lá là bệnh tim phổ biến, có nhiêu biến chứng nguy hiểm.Thay van hai lá cơ học ATS Open Pivot là phương pháp điêu trị tốt cho phân lớn bệnh nhân bị hẹp van hai lá. Sau mổ, tỷ lệ biến chứng thấp, tình trạng tăng áp lực động mạch phổi và suy tim cải thiện đáng kể theo thời gian. Hơn nữa với ưu điểm tiếng van nhỏ và giá thành thấp, van ATS Open Pivot sẽ làm tăng chất lượng sống cho bệnh nhân sau mổ.

\section{TÀI LIẸU THAM KHẢO}

1. Nguyễn Lân Viêt (2003). Thức hành bênh tim mạch, Nhà xuất bản Y học Hà Nội, tr.219 - 266.

2. Bonow RO., Carabello B., Leon A.C. Jr. (1998). ACC/AHA guidelines for the management of patients with valvular heart disease: a report of the American College of Cardiology/American Heart Association Task Force on Practice Guidelines (Committee on Management of Patients With Valvular Heart Disease). Journal of American College of Cardiology, 32 (5), pp. $1486-1588$.

3. Butchart EG (2001). Twenty years' experience with the Metronic Hall Valve.J Thorac Cardiovasc Surg 2001, pp.1090-1100.

4.Yuichiro Kaminishi (2009). The ATS bileaflet prothetic heart valve. Mid-term result from single center. Journal of American College of Cardiology, 30, pp. 1230-1238.

5. Nguyến Đức Hiền, Bùi Đức Phú(2007). Đánh giá kết quả phấu thuât thay van hai lá cơ hoc ơ bênh nhân hẹp van hai lá. Tap chí tim mạch học thành phố Hồ Chí Minh số 11 năm 2007.

6. Đăng Hanh Sơn (2010). Nghiên cứu đánh giá kểt quả phẩu thuật thay van hai lá bằng van cơ học Sorin tại Bênh viên Tim Hà Nội. Luận án Tiến sĩ y học, Học viện Quẩn y.

7. Đoàn Quốc Hửng, Nguyễn Duy Thắng (2012) Nghiên cứu đặc điểm lâm sàng, cận lâm sàng và kết quả thay van cơ học tại Bệnh viện hữu nghị Việt Đức. Tạp chí Tim mạch học Việt Nam, số 61, $\operatorname{tr}$ 21-32.

8. Đố Xuâ̂n Hai (2019). Nghiên cứu đánh giá kết quả phẩu thuật thay van hai lá bằng van cơ học St.Jude tại Bệnh viện Trung ương Quân đội 108. Luận án tiến sĩ y học, Học viện Quân y.

\section{KẾT QUẢ ĐÎ̂̀U TRI CHẤN THƯƠNG SỌ NÃO Ở NGƯỜI CAO TUỔI TẠI BỆNH VIỆN ĐA KHOA TỈNH THÁI BÌNH}

\section{TÓM TẮT}

Mục tiêu: Nhận xét lâm sàng, tổn thương trên chụp cắt lớp vi tính và kết quả điêu trị chấn thương sọ não ở người cao tuổi. Phương pháp: Mô tả cắt ngang 161 bệnh nhân cao tuổi bị chấn thương sọ não điêu trị tại bệnh viện Đa khoa tỉnh Thái Bình trong thời gian từ tháng 2 đến tháng 8 năm 2020. Kết quả: $161 / 534$ bệnh nhân chiếm tỉ lề $(30,1 \%)$ gồm 101 nam $(62,7 \%), 60$ nữ $(37,3 \%)$; tuổi trung bình $71,1 \pm 8,8$; nguyên nhân tai nạn giao thông $51,6 \%$, tai nạn sinh hoat $42,8 \%$. Lâm sàng mức độ nhẹ chiếm đa số $(91,3 \%)$, mức độ trung bình $(6,2 \%)$, chỉ có $(2,5 \%)$ mức độ năng. Tổn thương trên phim cắt lớp vi tính: Máu tự dưới màng cứng cấp tính chiếm tỉ lệ cao nhất $(47,2 \%)$, chảy máu màng mềm $(28,6 \%)$, máu tụ ngoài màng cứng $(5,6 \%)$. Có 14 bệnh lý mạn tính được ghi nhân trong tổng số 161 bệnh nhân nhâp viện. Trong đó gặp nhiều nhất là tăng huyết áp $(24,2 \%)$, tiểu đường typ 2 gặp $(9,9 \%)$. Điều trị nội

*Trường Đại họ Y Dược Thái Bình

Chịu trách nhiệm chính: Vũ Minh Hải

Email: vuminhhai777@gmail.com

Ngày nhận bài: 5.4.2021

Ngày phản biên khoa hoc: 24.5.2021

Ngày duyệt bài: 3.6.2021
Vũ Minh Hải*

khoa chiếm đa số $(86,3 \%)$, chỉ có $(13,7 \%)$ phẫu thuât. Tình trang ra viên ổn định $90,7 \%$; di chứng nhe $4,3 \%$, di chứng chứng vừa $2,5 \%$, di chứng nặng 1,9\%. Tử vong $0,6 \%$. Kết luân: Chấn thương sọ não người cao tuối, nam giới chiếm tỉ lệ cao. Bệnh mạn tính đi kèm găp nhiều nhất là tiểu đường; Loại máu tu thường gặp là dưới màng cứng cấp tính $(47,2 \%)$, phẫu thuật chiếm $(13,7 \%)$. Kết quả ra viện ổn định chiếm $(90,7 \%)$. Tử vong $(0,6 \%)$.

Tư' khóa: chấn thương sọ não người cao tuổi; chấn thương sọ não

\section{SUMMARY \\ OUTCOMES OF GERIATRIC TRAUMATIC BRAIN INJURIES TREATMENT AT THAI BINH GENERAL HOSPITAL}

Objectives: To assess clinical characteristics, lesions on CT scan and treatment outcomes of traumatic brain injury in the elderly. Methods: Crosssectional descriptive study carried out among 161 elderly patients with traumatic brain injury treated at Thai Binh Provincial General Hospital during the period from February to August 2020. Results: 161/534 patients equalled $(30.1 \%)$, including 101 males $(62.7 \%), 60$ females $(37.3 \%) ;$ median age $71.1 \pm 8.8$; the most comme cause was traffic accidents which 